\title{
E-Poly-L-lysine Affects the Vegetative Growth, Pathogenicity and Expression Regulation of Necrotrophic Pathogen Sclerotinia sclerotiorum and Botrytis cinerea
}

\author{
Tao Zhou ${ }^{\dagger}$, He Liu $^{\dagger}$, Yuanmin Huang ${ }^{\dagger}$, Zehao Wang, Yuhang Shan, Yan Yue, Zihao Xia (D), Yue Liang, \\ Mengnan An *(D) and Yuanhua Wu
}

check for updates

Citation: Zhou, T.; Liu, H.; Huang, Y.; Wang, Z.; Shan, Y.; Yue, Y.; Xia, Z.; Liang, Y.; An, M.; Wu, Y. $\varepsilon$-Poly-L-lysine Affects the Vegetative Growth, Pathogenicity and Expression Regulation of Necrotrophic Pathogen Sclerotinia sclerotiorum and Botrytis cinerea. J. Fungi 2021, 7, 821. https://doi.org/ $10.3390 /$ jof7100821

Academic Editor: David S. Perlin

Received: 15 August 2021

Accepted: 27 September 2021

Published: 30 September 2021

Publisher's Note: MDPI stays neutral with regard to jurisdictional claims in published maps and institutional affiliations.

Copyright: (c) 2021 by the authors. Licensee MDPI, Basel, Switzerland. This article is an open access article distributed under the terms and conditions of the Creative Commons Attribution (CC BY) license (https:/ / creativecommons.org/licenses/by/ $4.0 /)$.
College of Plant Protection, Shenyang Agricultural University, Shenyang 110866, China; 2019220498@stu.syau.edu.cn (T.Z.); 2019200124@stu.syau.edu.cn (H.L.); 2019240320@stu.syau.edu.cn (Y.H.); 2020200136@stu.syau.edu.cn (Z.W.); 2019220469@stu.syau.edu.cn (Y.S.); 2020240487@stu.syau.edu.cn (Y.Y.); zihao8337@syau.edu.cn (Z.X.); yliang@syau.edu.cn (Y.L.); wuyh09@syau.edu.cn (Y.W.)

* Correspondence: anmengnan@syau.edu.cn

t These authors contributed equally to this work.

\begin{abstract}
Microbial secondary metabolites produced by Streptomyces are applied to control plant diseases. The metabolite, $\varepsilon$-poly-L-lysine ( $\varepsilon$-PL), is a non-toxic food preservative, but the potential application of this compound as a microbial fungicide in agriculture is rarely reported. In this study, the effect and mode of action of $\varepsilon$-PL on two necrotrophic pathogenic fungi, Sclerotinia sclerotiorum and Botrytis cinerea, were investigated. The results showed that $\varepsilon$-PL effectively inhibited the mycelial growth of S. sclerotiorum and B. cinerea with $\mathrm{EC}_{50}$ values of $283 \mu \mathrm{g} / \mathrm{mL}$ and $281 \mu \mathrm{g} / \mathrm{mL}$, respectively. In addition, $\varepsilon$-PL at the dose of 150 and $300 \mu \mathrm{g} / \mathrm{mL}$ reduced $S$. sclerotiorum sclerotia formation. The results of the RNA-seq and RT-qPCR validation indicated that $\varepsilon$-PL significantly regulated the gene expression of critical differential expressed genes (DEGs) involved in fungal growth, metabolism, pathogenicity, and induced an increase in the expression of the fungal stress responses and the detoxification genes. These results provided new insights for understanding the modes of action of $\varepsilon$-PL on S. sclerotiorum and B. cinerea and improved the sustainable management of these plant diseases.
\end{abstract}

Keywords: $\varepsilon$-PL; necrotrophic fungi; transcriptomic analysis; anti-fungal modes of action

\section{Introduction}

Plant diseases caused by fungal pathogens result in significant economic losses in agriculture production [1]. Sclerotinia sclerotiorum (Lib.) de Bary is a filamentous ascomycete and an important plant pathogen [2,3]. This fungal pathogen poses a threat to dicotyledonous crops such as sunflower, soybean, peanut, oilseed rape, lentils and various vegetables, but also monocotyledonous species such as onion, tulip, and garlic [4]. This fungus can produce sclerotia, which serve as long-term survival structures under adverse environments and play critical roles in disease progression [5,6]. Another necrotrophic pathogen, Botrytis cinerea, causes grey mold disease in a variety of fruit and vegetables [7]. It is widely accepted that $S$. sclerotiorum and $B$. cinerea are closely related based on their genome sequences $[7,8]$. Plant-pathogenic fungi can facilitate an infection in their hosts by the secretion of a wide array of cell-wall-degrading enzymes (CWDEs), including cellulases (glucanase), pectinases (polygalacturonase), glycosidases, xylanases and cutinases [5,6]. In addition, $S$. sclerotiorum and $B$. cinerea are known to produce oxalic acid to promote infection [7]. Some lines of chemical or biological fungicides were reported to suppress gray mold disease caused by B. cinerea, while reports of the effective agents on S. sclerotiorum are very limited [9].

The large-scale and long-term use of chemical synthetic pesticides may enhance the pesticide resistance of pathogens, reduce pesticide sensitivity, negatively affect the ecolog- 
ical environment and pose a threat to human health $[10,11]$. Compared with traditional chemical pesticides, the microbial source pesticides have various advantages in biodegradability and environmental compatibility $[12,13]$. Streptomyces species are major members of actinomycetes and can produce a large variety of secondary metabolites with potential anti-microbial activities $[13,14]$. For instance, $\varepsilon$-poly-L-lysine ( $\varepsilon-P L)$, produced by S. albulus or S. griseofuscus, is a homopolymer of L-lysine with a polymerization degree of approximately $25-35$ and connected by a peptide bond between the $\alpha$-carboxy group and the $\varepsilon$-amino group $[15,16]$.

The compound $\varepsilon$-PL is applied as a food preservative that exhibits a good anti-bacterial activity and can be degraded into lysine and absorbed as an essential amino acid by the human body without any harmful influence [17]. Additionally, $\varepsilon-P L$ is used as an interferon inducer, drug delivery vehicle and gene delivery vector and used in medical research [18]. The anti-bacterial activity of $\varepsilon$-PL was well investigated using Escherichia coli, Staphylococcus aureus, and Pseudomonas aeruginosa $[17,19,20]$, while recent research focused on its effect on other plant pathogens, including viruses and fungi [21-23]. Our previous study showed that $\varepsilon$-PL significantly suppressed the infection of the tobacco mosaic virus (TMV) in Nicotiana glutinosa, as well as RNA accumulation in tobacco protoplasts and induced host defensive responses [24,25]. In addition, we indicated that $\varepsilon$-PL effectively inhibited vegetative growth and pathogenicity and affected the respective gene expression of Alternaria alternata [21]. Recent studies revealed that $\varepsilon$-PL exhibited effective antifungal activity against Penicillium digitatum [22]. Furthermore, $\varepsilon$-PL was reported to effectively inhibit the incidence of grey mold rot on various fruits and vegetables caused by $B$. cinerea $[23,26]$. The high-throughput sequencing techniques, such as Illumina RNA-seq, provided a powerful tool to investigate the transcriptome variations of the pathogenic fungi in response to biological agents $[27,28]$.

In this research, the microbial source agent $\varepsilon$-PL significantly suppressed mycelial growth and regulated the expression of the critical genes involved in fungal growth, pathogenicity, and the stress responses and detoxification of necrotrophic fungi, S. sclerotiorum and B. cinerea. Such results provided new insights for the mode of action of $\varepsilon$-PL in the management of plant diseases caused by S. sclerotiorum and B. cinerea.

\section{Materials and Methods}

\subsection{Preparation of Microbial Agent $\varepsilon-P L$}

The compound $\varepsilon$-PL was identified and purified from Streptomyces microflavus var. liaoningensis with molecular mass in the range of 3454-4352 Da with approximately 25-35 residues [24].

\subsection{Pathogenic Fungi and Plants}

The pathogenic fungi, S. sclerotiorum and B. cinerea [29], were preserved in College of Plant Protection, Shenyang Agricultural University, China [29,30]. Mycelia cultured on PDA (potato dextrose agar, $20 \mathrm{~g}$ agar powder, $20 \mathrm{~g}$ D-glucose, $200 \mathrm{~g}$ potato) at $25^{\circ} \mathrm{C}$ were used in subsequent experiments of mycelial growth and inoculation experiments. Rapeseed plants (Brassica napus cultivar Westar) were grown in an artificial climate greenhouse at a constant temperature of $25^{\circ} \mathrm{C}, 16 \mathrm{~h}$ light $/ 8 \mathrm{~h}$ dark.

\subsection{Antifungal Activity of $\varepsilon$-PL In Vitro}

The antifungal activity of $\varepsilon$-PL on S. sclerotiorum, as well as B. cinerea, was tested by measuring mycelial growth in vitro. The PDA medium containing $\varepsilon$-PL solution was adjusted to the final concentrations of $100,200,300,600$ and $1200 \mu \mathrm{g} / \mathrm{mL}$, while the PDA without $\varepsilon$-PL solution served as a control, respectively. The mycelial plugs (5 $\mathrm{mm}$ in diameter) were placed in the center of the PDA plates and cultured in a $25^{\circ} \mathrm{C}$ incubator. The growth of fungal colony was measured at 3-day post inoculation (dpi) for S. Sclerotinia and $4 \mathrm{dpi}$ for $B$. cinerea with three inoculation replicates of each pathogen; the growth assays were independently repeated three times. The inhibition rate of $\varepsilon-\mathrm{PL}$ on the mycelial growth 
of S. sclerotiorum and B. cinerea was calculated by the following formula [31]: antifungal rate $(\%)=[($ control - treated $) /$ control $] \times 100 \%$. The effective medium concentration $\left(\mathrm{EC}_{50}\right)$ values of the agent on S. sclerotiorum and B. cinerea were calculated.

Furthermore, the antifungal activity of $\varepsilon$-PL on sclerotial development of S. sclerotiorum was evaluated [32]. Sclerotial formation was estimated in different concentrations $(50,100$, 150,200 and $300 \mu \mathrm{g} / \mathrm{mL}$ ) of $\varepsilon$-PL treatment after 9 dpi while the PDA without $\varepsilon$-PL solution served as a control. Sclerotia were collected and air-dried at $70^{\circ} \mathrm{C}$ for $4 \mathrm{~h}$ and then the biomass was weighed. Antifungal activity estimation was independently conducted five times.

\subsection{Antifungal Activity of $\varepsilon$-PL on Detached Leaves}

Mycelial plugs ( $5 \mathrm{~mm}$ ) of $S$. sclerotiorum were directly placed on the excised rapeseed leaves that were prewounded by syringe needle for pathogen inoculation. After $12 \mathrm{hpi}$, the inoculated leaves were sprayed with a series of concentrations of $\varepsilon$-PL at 200, 400, 600 and $1200 \mu \mathrm{g} / \mathrm{mL}$ while the water spray served as a mock. The inoculated leaves were consistently incubated at $22{ }^{\circ} \mathrm{C}$ and the lesion was photographed at $24 \mathrm{hpi}$. The necrotic lesions were quantified by Assess software (APS Press, St. Paul, MN, USA). Each inoculation with each concentration of $\varepsilon$-PL treatment was performed with five leaves and the inoculation assays were independently repeated three times.

\section{5. cDNA Library Construction and Illumina Sequencing}

Total RNA was extracted from the mock or $280 \mu \mathrm{g} / \mathrm{mL}$ ( $\mathrm{EC}_{50}$ concentration) of $\varepsilon$-PLtreated S. sclerotiorum, as well as B. cinerea, collected from a Petri dish at $3 \mathrm{dpi}$ using TRIzon Reagent (TIANGEN, Beijing, China) and subsequently used for RNA-seq. The sequencing libraries were constructed using NEBNext UltraTM RNA Library Prep Kit (NEB, Ipswich, MA, USA) following the manufacturer's instructions. The mRNA was purified from total RNA using poly-T oligo-attached magnetic beads and fragmented using divalent cations at elevated temperatures in NEBNext First Strand Synthesis Reaction Buffer (5X). The cDNA was synthesized and purified with AMPure XP system (Beckman Coulter, Beverly, NJ, USA) to select approximately $240 \mathrm{bp}$ fragments. The size-selected, adaptor-ligated cDNA was treated with USER Enzyme (NEB, Ipswich, MA, USA) before PCR. Then, the purified PCR products were analyzed by an Illumina sequencing platform (Illumina NovaSeq 6000; Biomarker, Beijing, China).

The raw reads generated by Illumina sequencing were submitted to the Sequence Read Archive database at NCBI (SRA, http:/ / www.ncbi.nlm.nih.gov/Traces/sra, accessed on 19 July 2021) with the SRA BioProject accession number PRJNA749671 ( $\varepsilon$-PL or mock treated S. sclerotiorum samples); PRJNA749479 ( $\varepsilon$-PL- or mock-treated B. cinerea samples). The clean reads were mapped to the reference genome sequence using Hisat2 tools soft (http:/ /ccb.jhu.edu/software/hisat2/index.shtml, accessed on 18 February 2021). Differential expression analysis of $\varepsilon$-PL-Ss (S. sclerotinia treated with $\varepsilon$-PL) versus mockSs (S. sclerotinia treated with distilled water), and $\varepsilon$-PL-Bc (B. cinerea treated with $\varepsilon$ $\mathrm{PL})$ vs. mock-Bc (B. cinerea treated with distilled water) were performed using the DEseq (http:/ / www.bioconductor.org/packages/release/bioc/html/DESeq.html, accessed on 21 February 2021). The differential expressed genes (DEGs) were determined by adjusting the false discovery rate $<0.05$. To further analyze these DEGs, Gene Ontology (GO) as well as Kyoto Encyclopedia of Genes and Genomes (KEGG) pathway (http:/ / www.genome.jp/kegg/, accessed on 25 February 2021) were conducted.

\subsection{Reverse-Transcription Quantitative PCR (RT-qPCR) Assay}

The $\varepsilon$-PL $\left(\mathrm{EC}_{50}\right.$ concentration) or distilled water treated S. sclerotiorum or B. cinerea mycelium were collected at $3 \mathrm{dpi}$. The total extracted RNA was subjected to reversetranscription using a FastKing RT Kit (TIANGEN). The primer sets were designed within the CDS region of nucleotide sequences of $S$. sclerotiorum or B. cinerea. Then, RT-qPCR analysis was conducted using ChamQ Universal SYBR qPCR Master Mix (Vazyme, Nan- 
jing, China) on StepOne Plus real-time PCR system (Thermo Fisher Scientific). Relative expression of each gene was assessed by $2^{-\Delta \Delta C}$ method with the normalization using actin of S. sclerotiorum (SS1G_08733) or B. cinerea (BC1G_13894) as a reference gene by three biological replicates.

\subsection{Statistical Analysis}

All of the data were statistically analyzed by one-way analysis of variance (ANOVA) $(p<0.05)$ and then the means were separated by Tukey's multiple comparison test $(p<0.05)$ using SAS software (version 9.1; SAS Institute Inc., Cary, NC, USA).

\section{Results}

\section{1. $\varepsilon$-PL Inhibit Growth and Development of S. sclerotiorum and B. cinerea}

The inhibitory effect on mycelial growth and the sclerotial development of S. sclerotiorum at a series of concentrations of $\varepsilon$-PL was investigated. The results indicated that the increased concentration of $\varepsilon$-PL treatment gradually inhibited the growth of S. sclerotiorum. Especially, the inhibition of mycelium growth was observed at 100, 200, 300 and $600 \mu \mathrm{g} / \mathrm{mL}$, while at $1200 \mu \mathrm{g} / \mathrm{mL}$ the mycelium growth was completely inhibited (Figure 1a). Particularly, $\varepsilon-\mathrm{PL}$ at the concentration of 300 and $600 \mu \mathrm{g} / \mathrm{mL}$ significantly suppressed the mycelial growth of S. sclerotiorum (Figure 1b), while $100 \mu \mathrm{g} / \mathrm{mL}$ of $\varepsilon$-PL and lower concentrations did not exhibit an effective inhibitory effect. The inhibition rate of $\varepsilon$-PL at different concentrations on S. sclerotiorum is shown in Table S1. For example, the inhibition rates of $\varepsilon$-PL at 200, 300 and $600 \mu \mathrm{g} / \mathrm{mL}$ on S. sclerotiorum were $40.35 \pm 3.88 \%, 58.16 \pm 1.01 \%$ and $75.29 \pm 1.22 \%$, respectively. Another necrotrophic fungus, B. cinerea, was also used to test the antifungal effect of $\varepsilon$-PL and the inhibition rate caused by the treatment of different concentrations of $\varepsilon$-PL was generally consistent with that of S. sclerotiorum (Figure 1c,d). The $\mathrm{EC}_{50}$ of $\varepsilon-\mathrm{PL}$ was determined as $283 \mu \mathrm{g} / \mathrm{mL}$ and $281 \mu \mathrm{g} / \mathrm{mL}$ based on the mycelial growth of $S$. sclerotiorum and B. cinerea at the different concentrations of $\varepsilon$-PL treatments, respectively. The results indicated that $\varepsilon$-PL could inhibit the mycelial growth of $S$. sclerotiorum and B. cinerea.

Our results also showed that 150 and $300 \mu \mathrm{g} / \mathrm{mL}$ of $\varepsilon$-PL treatment significantly inhibited the sclerotial formation, such as the numbers and the dry weight of sclerotia, but did not affect the sclerotial formation under $100 \mu \mathrm{g} / \mathrm{mL} \varepsilon$-PL treatment (Figure 2).

\subsection{Inhibition of $\varepsilon$-PL on Infection of S. sclerotiorum and B. cinerea In Vivo}

Subsequently, the inhibitory effect of $\varepsilon$-PL treatment on the infection of S. sclerotiorum was investigated using detached leaves of rapeseed. The results showed that the increased concentrations of $\varepsilon$-PL at 400, 600 and $1200 \mu \mathrm{g} / \mathrm{mL}$ progressively inhibited the necrotic lesion formed by S. sclerotiorum (Figure 3). Specially, the 600 and $1200 \mu \mathrm{g} / \mathrm{mL} \varepsilon$-PL concentrations reduced the lesion area by $47.23 \%$ and $76.28 \%$, respectively (Figure $3 b$ ). Meanwhile, $200 \mu \mathrm{g} / \mathrm{mL}$ and lower concentrations of the agent treatment did not exhibit an observable inhibitory effect (Figure $3 b$ ). In addition, the inhibitory effect of $\varepsilon-P L$ on $B$. cinerea was tested using tomato and pear fruits. The results indicated the effective inhibitory effect of 600 to $1500 \mu \mathrm{g} / \mathrm{mL}$ of $\varepsilon$-PL on the infection of B. cinerea in planta by reducing the area of the necrotic lesion approximately 2- to 5 -fold (data not shown), which was generally consistent with previous reports [33].

\subsection{Transcription Analysis of S. sclerotiorum and B. cinerea Affected by $\varepsilon-P L$}

RNA-Seq has recently become a powerful tool for transcriptome profiling in studies monitoring fungal transcriptional responses $[27,28]$. Based on the inhibition effects of $\varepsilon$-PL on S. sclerotiorum and B. cinerea, a genome-wide gene expression analysis was conducted to further investigate the effect of $\varepsilon-\mathrm{PL}$ on the modulation of the critical genes or pathways of $S$. sclerotiorum and B. cinerea. The in vitro $\varepsilon$-PL- or mock-treated mycelium of the two pathogenic fungi were collected and subjected to RNA-seq. A total of $24.89 \mathrm{~Gb}$ raw reads were obtained and the clean reads were mapped to the reference genome database 
of S. sclerotiorum (ASM14694v1) and B. cinerea (ASM14353v4), respectively. There were $19,508,204$ and 22,306,964 clean reads from the $\varepsilon$-PL treatment and control libraries of $S$. sclerotiorum; and 19,850,423 and 20,176,913 clean reads from the $\varepsilon$-PL treatment and control libraries of B. cinerea, respectively (Table S2).

(a)

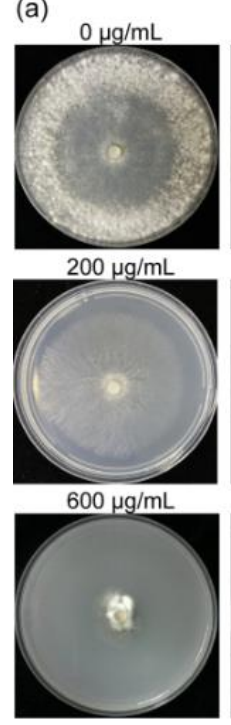

(b)

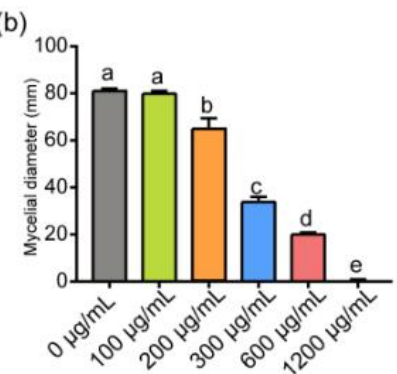

(c)
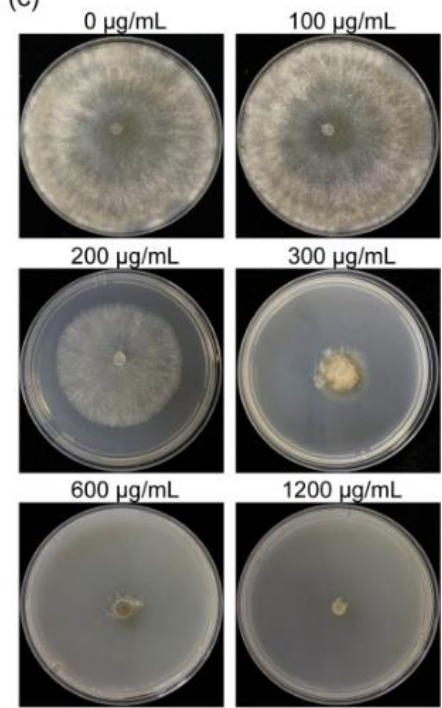

(d)

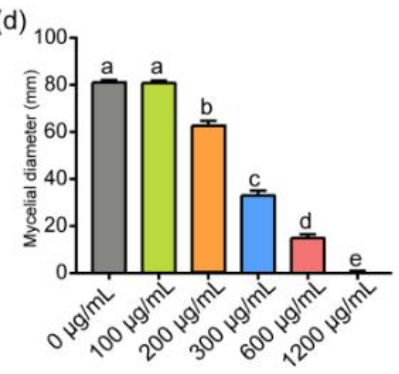

Figure 1. Effects of different concentrations of $\varepsilon$-PL on the mycelial growth of Sclerotinia sclerotiorum and Botrytis cinerea. (a) Colonies of S. sclerotiorum treated with $\varepsilon$-PL at concentrations of 0,100 , 200, 300, 600 and $1200 \mu \mathrm{g} / \mathrm{mL}$ at 3 dpi. (b) Mycelial growth of S. sclerotiorum affected by different concentrations of $\varepsilon$-PL. (c) Colonies of B. cinerea treated with $\varepsilon$-PL at concentrations of $0,100,200,300$, 600 and $1200 \mu \mathrm{g} / \mathrm{mL}$ at 4 dpi. (d) Mycelial growth of $B$. cinerea affected by different concentrations of $\varepsilon$-PL. Different letters indicate significant differences $(p<0.05)$.

Volcano plot, and $\log _{2}$-fold change ( $\log _{2} \mathrm{FC}$ ) showed the comparison of DEGs between the mock- and $\varepsilon$-PL-treated group (Figure 4). A total of 262 DEGs were identified in S. sclerotiorum, which included 168 up-regulated DEGs and 94 down-regulated DEGs in S. sclerotiorum (Table S3). Meanwhile a total of 411 DEGs were identified in B. cinerea, including 325 genes which were up-regulated and 86 genes which were down-regulated (Table S4). The DEGs were mainly classified in the terms of biological processes, cellular components and molecular functions in the GO analysis (Figure S1), in which metabolic, cellular and single-organism processes, in the terms of biological process; cell, organelle and membrane components, in the terms of cellular components; and catalytic, binding and transporter activity, in the terms of biological processes, were enriched in S. sclerotiorum and B. cinerea (Figure S1). Additionally, the total annotation of the DEGs in KEGG pathways were shown (Figure 5). The " $\varepsilon$-PL-Ss vs. mock-Ss", "starch and sucrose metabolism", "Valine, leucine and isoleucine degradation," as well as "propanoate metabolism" were the most enriched pathways. In contrast, the pathways involved in "ribosome biogenesis", "glycine, serine and threonine metabolism" and "ABC transporters" were enriched in " $\varepsilon-\mathrm{PL}-\mathrm{Bc}$ vs. mock-Bc" (Figure 5). 
(a)
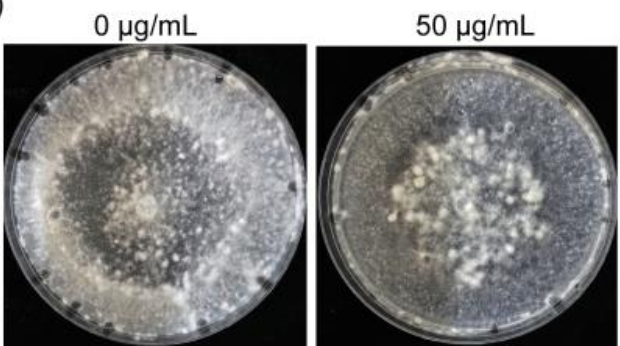

$100 \mu \mathrm{g} / \mathrm{mL}$

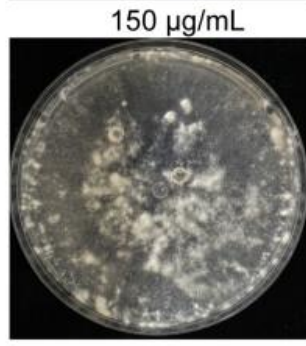

$200 \mu \mathrm{g} / \mathrm{mL}$
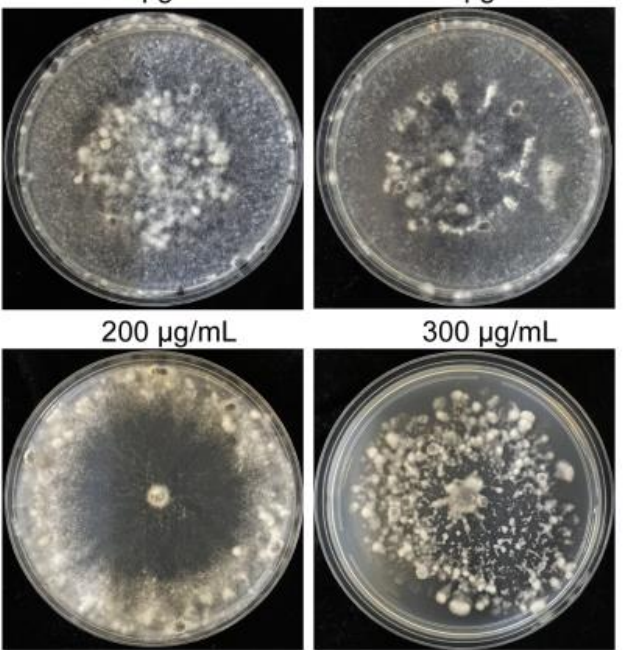

$300 \mu \mathrm{g} / \mathrm{mL}$

(b)

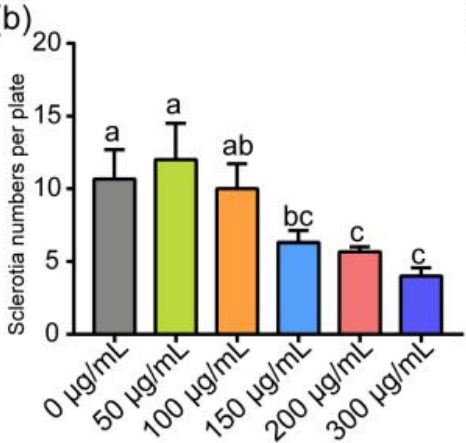

(c)

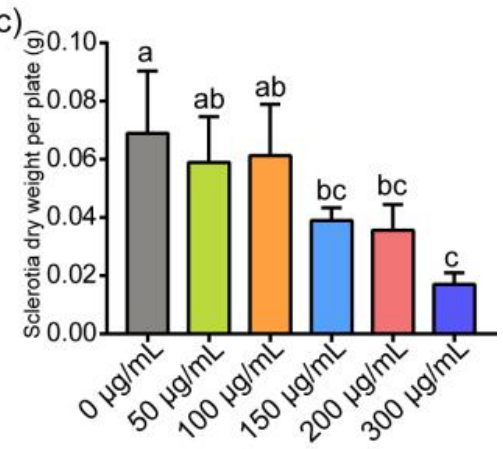

Figure 2. Effects of 0,50,100,150, 200 and $300 \mu \mathrm{g} / \mathrm{mL} \varepsilon$-PL treatment on the number, morphology and dry weight of sclerotia produced by Sclerotinia sclerotiorum at $9 \mathrm{dpi}$. (a) $\varepsilon$-PL treatment higher than $150 \mu \mathrm{g} / \mathrm{mL}$ affected the formation and morphology of sclerotia. (b) Effect of different concentrations of $\varepsilon$-PL on the number of sclerotia. (c) Effect of different concentrations of $\varepsilon$-PL on the dry weight of sclerotia. Different letters indicate significant differences $(p<0.05)$.

(a)

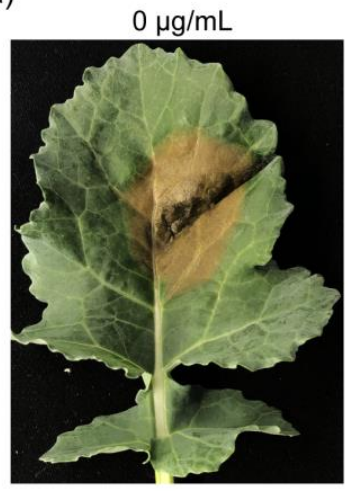

$600 \mu \mathrm{g} / \mathrm{mL}$

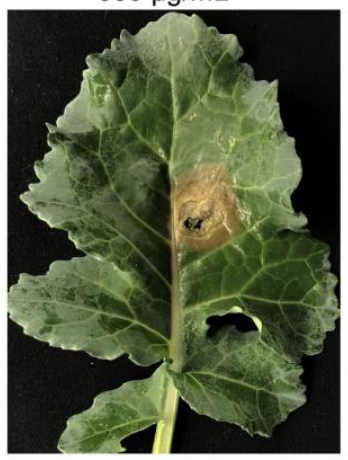

(b)

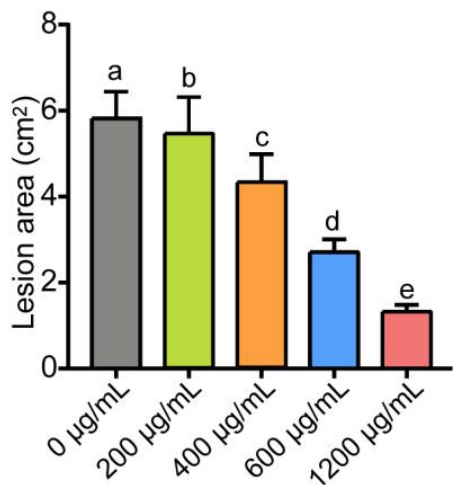

Figure 3. Effects of $0,200,400,600$ and $1200 \mu \mathrm{g} / \mathrm{mL}$ of $\varepsilon-\mathrm{PL}$ on the infection of Sclerotinia sclerotiorum on rapeseed leaves. (a) $\varepsilon$-PL at $600 \mu \mathrm{g} / \mathrm{mL}$ significantly reduced necrotic lesion area caused by infection of S. sclerotiorum. (b) Effect of different concentrations of $\varepsilon$-PL on the necrotic lesion induced by $S$. sclerotiorum. Different letters indicate significant differences $(p<0.05)$. 

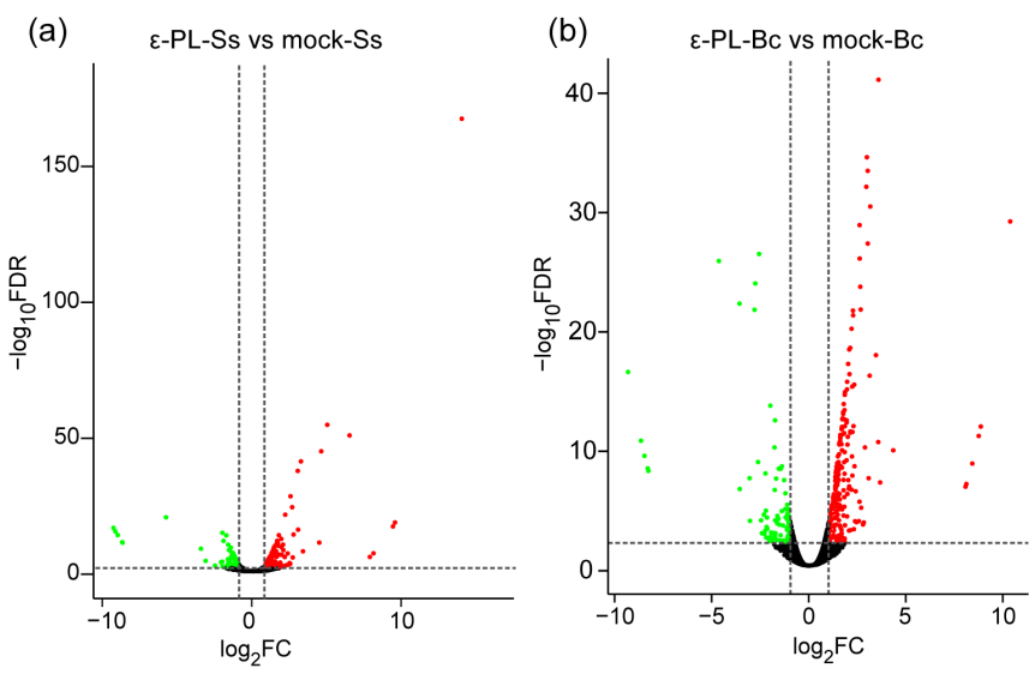

Figure 4. Volcano plots showing differential expressed genes (DEGs) of $\varepsilon$-PL-treated Sclerotinia sclerotiorum (a) $\varepsilon$-PL-Ss vs. mock-Ss or Botrytis cinerea (b) $\varepsilon$-PL-Bc vs. mock-Bc compared with mock. The red and green colors represent the significantly up- and down-regulated genes, respectively $\left(\mathrm{FDR}<0.05\right.$ and $\left.\mid \log _{2} \mathrm{FCl} \geq 1\right)$.

(a)

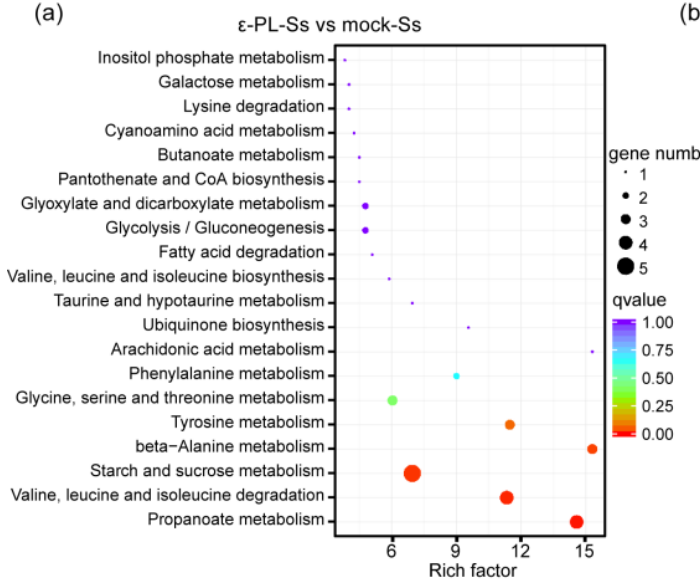

(b)

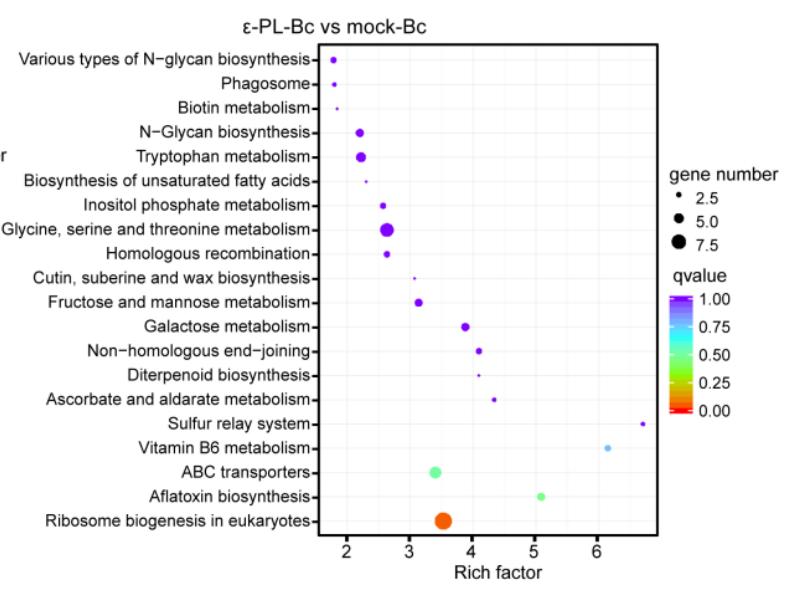

Figure 5. Kyoto Encyclopedia of Genes and Genomes (KEGG) pathways of the enriched DEGs of (a) $\varepsilon$-PL-Ss vs. mock-Ss and (b) $\varepsilon$-PL-Bc vs. mock-Bc. The rich factor reflects the degree of enriched DEGs in a given pathway. The number of enriched DEGs in the pathway is shown by the circle area, and the circle color represents the ranges of the corrected $p$-value.

\subsection{Gene Expression Involved in the Growth and Pathogenicity, Metabolism, Stress Responses and Detoxification}

Metabolism is central to microbial life [34], and the results of RNA-seq showed that a variety of genes involved in carbohydrate or amino acid metabolism were differentially regulated (Figure 6; Table 1, Tables S3 and S4). Several critical DEGs involved in metabolism and fungal growth were listed in Table 1 and the underlined DEGs were subjected to RTqPCR to verify their expressions. The specific amplification primers were listed in Table S5. The results showed that expression levels of alpha-amylase A (SsAmy3, SS1G_13472), meiotic activator RIM4 (SsRIM4, SS1G_03997), glutaminase A (SsGtaA, SS1G_08889 and BcGtaA, BC1G_10486) were reduced in $S$. sclerotiorum or $B$. cinerea treated by $\varepsilon$-PL (Figure 6a). Specifically, the expression levels of the ribosomal export protein NMD3 (BC1G_03554) were increased by $\varepsilon$-PL treatment in $B$. cinerea (Figure $6 \mathrm{~b}$ ). Such results were consistent with the those of the RNA-seq. 


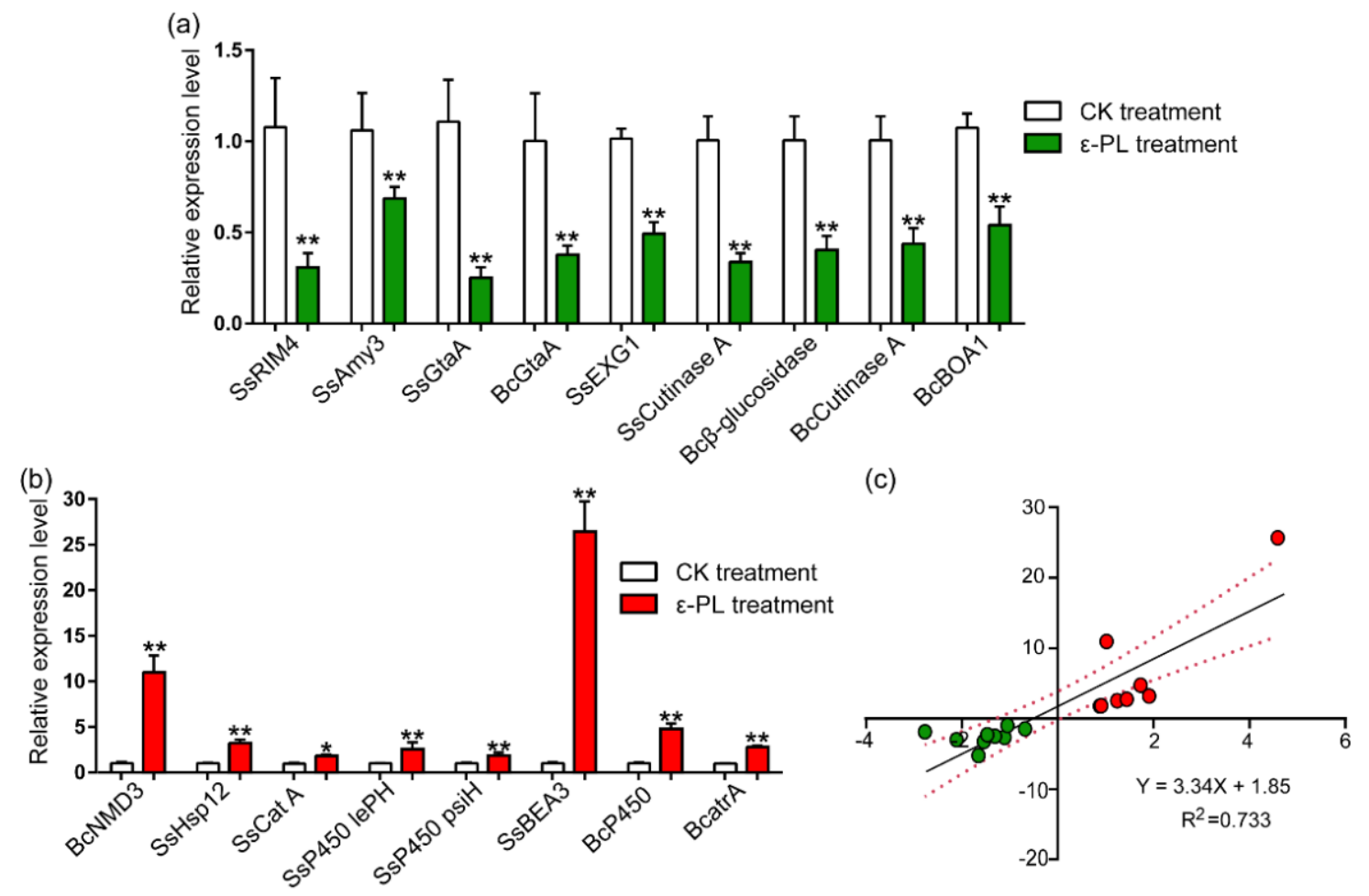

Figure 6. RT-qPCR verification of the regulation of 17 DEGs from $\varepsilon$-PL-treated Sclerotinia sclerotiorum or Botrytis cinerea. (a) DEGs mainly involved in fungal growth, or metabolites and pathogenicity, were down-regulated by $\varepsilon$-PL. (b) DEGs mainly involved in fungal stress response and detoxification were up-regulated by $\varepsilon$-PL. (c) Regression analysis of RNA-seq (independent variable) and RT-qPCR (dependent variable) data to evaluate their correlation by GraphPad Prism 7. Asterisk “*” indicated significant difference $(p<0.05)$ and " "**" indicated extremely significant difference $(p<0.01)$ by $\varepsilon$-PL treatment compared with control treatment. Red color represents up-regulated genes while green color represents down-regulated genes.

The release of toxins or cell-wall-degrading enzymes is the primary infection process of pathogenic fungi [35-37]. In this study, $\varepsilon$-PL generally decreased the expression of various genes encoding cell-wall-degrading enzymes, such as cellulase, pectate lyase, cutinase, and polysaccharide monooxygenase (Figure 6; Table 1, Tables S3 and S4). The RT-qPCR analysis confirmed that the expression of several cell-wall-degrading enzyme genes, as well as other genes required for pathogenicity, such as glucan 1,3-beta-glucosidase (SsEXG1, Ss1G_09216), cutinase A (SS1G_13386; BC1G_02936), beta-glucosidase I (BC1G_13346), and oxidoreductase (BcBOA1, BCIN_01g00010) were significantly decreased by $\varepsilon$-PL in S. sclerotiorum or $B$. cinerea (Figure 6a). These results were consistent with the results of the RNA-seq.

The transcriptomic results showed that $\varepsilon$-PL also induced the significant differential expression of genes involved in fungal stress responses, such as heat shock and detoxification proteins, including the cytochrome P450s and ABC transporters in S. sclerotiorum and B. cinerea (Figure 6; Table 1, Tables S3 and S4). The RT-qPCR were performed to validate the expressions of heat shock protein 12 (SsHsp12,SS1G_05007), catalase A (SscatA, SS1G_05200), cytochrome P450 monooxygenases (SslepH, SS1G_00119; SspsiH, SS1G_00121; BcAN1958, BC1G_u), and ABC transporters (SsBEA3, SS1G_04757; BcatrA, BC1G_02800) in $S$. sclerotiorum or $B$. cinerea treated by $\varepsilon$-PL. The results showed that the expression of these tested genes significantly increased after $\varepsilon$-PL treatment in S. sclerotiorum and B. cinerea (Figure $6 \mathrm{~b}$ ). Additionally, regression analyses showed that there was a positive correlation between the RNA-seq and RT-qPCR data (Figure 6c). 
Table 1. A general table showing critical DEGs involved in fungus growth and metabolism, pathogenicity, stress response and detoxification induced by $\varepsilon$-PL.

\begin{tabular}{|c|c|c|c|c|c|}
\hline Gene Category & Gene Description & $\log _{2} \mathrm{FC}$ & Regulate & Gene Functions & References \\
\hline \multicolumn{6}{|c|}{ Fungus growth and metabolism } \\
\hline SS1G_09392 & glucoamylase & 1.42 & up & starch metabolism & [38] \\
\hline SS1G_04563 & phosphatidylserine decarboxylase & -2.51 & down & growth and morphogenesis & [39] \\
\hline SS1G_03997 & meiotic activator RIM4 & -1.54 & down & required for meiosis & [40] \\
\hline SS1G_13472 & $\overline{\text { alpha-amylase A amy3 }}$ & -0.68 & down & starch metabolism & [41] \\
\hline SS1G_08889 & glutaminase $\mathrm{A}$ & -1.65 & down & glutamic acid synthesis & [42] \\
\hline BC1G_10486 & $\frac{\bar{g} \text { glutaminase A }}{}$ & -1.11 & down & glutamic acid synthesis & [42] \\
\hline BC1G_03554 & ribosomal export protein NMD3 & 1.02 & up & mRNA and rRNA export & [43] \\
\hline \multicolumn{6}{|l|}{ Pathogenisis } \\
\hline SS1G_06037 & glucan 1,3-beta-glucosidase & -0.75 & down & cell wall degradation & [36] \\
\hline SS1G_09216 & glucan 1,3-beta-glucosidase EXG1 & -1.05 & down & pectin degradation & [36] \\
\hline SS1G_13386 & cutinase A & -2.11 & down & cuticle degradation & [44] \\
\hline SS1G_09821 & polysaccharide monooxygenase & 1.47 & up & lignin or cellulose degradation & [37] \\
\hline SS1G_12413 & serine carboxypeptidase & -1.03 & down & virulence determinants & [45] \\
\hline BC1G_13346 & probable beta-glucosidase I & -1.31 & down & cell wall degradation & [36] \\
\hline BC1G_02936 & cutinase $\mathrm{A}$ & -1.47 & down & plant cuticle degradation & [44] \\
\hline BC1G_09000 & probable pectate lyase & -1.08 & down & cell wall degradation & [36] \\
\hline BCIN_01g00010 & oxidoreductase BOA1 & -2.77 & down & putative botcinic acid synthesis & {$[46]$} \\
\hline BC1G_16083 & FAD-binding monooxygenase BOA2 & -2.81 & down & putative botcinic acid synthesis & [46] \\
\hline \multicolumn{6}{|l|}{ Stress response } \\
\hline SS1G_05007 & $12 \mathrm{kDa}$ heat shock protein & 1.91 & up & stress response & [47] \\
\hline SS1G_05200 & $\overline{\text { catalase A (catA) }}$ & 0.88 & up & stress response & [48] \\
\hline BC1G_14178 & heat shock protein 16 & 1.35 & up & stress response & \\
\hline BC1G_12146 & catalase 7 (cat 7) & 1.42 & up & stress response & [48] \\
\hline \multicolumn{6}{|l|}{ Detoxification } \\
\hline SS1G_00119 & cytochrome P450 monooxygenase lepH & 1.24 & up & metabolizing enzymes & [49] \\
\hline SS1G_00121 & cytochrome P450 monooxygenase psiH & 0.91 & up & metabolizing enzymes & [49] \\
\hline SS1G_11948 & MFS-type transporter SPBC409.08 & 1.77 & up & efflux transport & [50] \\
\hline SS1G_02254 & $\mathrm{ABC}$ transporter $\mathrm{ARB}$ & 0.84 & up & efflux transport & [51] \\
\hline SS1G_04757 & $\mathrm{ABC}$ transporter $\mathrm{BEA} 3$ & 4.59 & up & efflux transport & [51] \\
\hline SS1G_00727 & aldo-keto reductase yakc & 3.02 & up & detoxification & [52] \\
\hline BC1G_13302 & $\begin{array}{l}\text { cytochrome P450 monooxygenase } \\
\text { AN1598 }\end{array}$ & 1.73 & up & metabolizing enzymes & [49] \\
\hline BC1G_13299 & glutathione S-transferase like protein tpcF & 1.33 & up & conjugating enzymes & [49] \\
\hline BC1G_00798 & MFS-type transporter astH & 1.23 & up & efflux transport & [50] \\
\hline BC1G_05984 & $\mathrm{ABC}$ multidrug transporter atrI & 1.81 & up & efflux transport & [53] \\
\hline BC1G_02800 & $\mathrm{ABC}$ multidrug transporter atrA & 1.44 & up & efflux transport & [53] \\
\hline
\end{tabular}

Genes selected for RT-PCR verification were underlined.

\section{Discussion}

The $\varepsilon$-PL was mainly applied to inhibit bacteria and was well-characterized as a food preservative [54]. In the previous study, we investigated the functions of $\varepsilon$-PL on the induction of host defense responses against the infection of the tobacco mosaic virus (TMV) [25], as well as the anti-fungal mechanisms of $\varepsilon-\mathrm{PL}$ on A. alternata [21]. The $\varepsilon-\mathrm{PL}$ was reported to effectively inhibit the incidence of grey mold rot on various fruits and vegetables caused by B. cinerea $[23,26]$. A study of the mode of action indicated that $\varepsilon-\mathrm{PL}$ treatment could suppress fungal infection by inducing leakages of intercellular electrolytes or proteins and increasing the membrane permeability of B. cinerea [23]. Furthermore, $\varepsilon-\mathrm{PL}$ was also reported to directly act against the pathogenic fungi, A. alternata, by disturbing pathogen membrane integrity [55]. In addition, $\varepsilon$-PL showed an inhibitory activity on the spore germination of Drechslera erythrospila, B. cinerea, and Phytophthora infestans [56].

The next-generation sequencing techniques are powerful tools to reveal the transcriptome variations of $S$. sclerotiorum and B. cinerea during infection and to respond to fungicides or biological agents $[28,35,57]$. For example, global gene expression using RNA-seq was performed to reveal the gene regulation of S. sclerotiorum during the infection of Glycine max [35]. In addition, transcriptome sequencing was used to analyze the gene expression of S. sclerotiorum treated with the fermentation broth of Bacillus amyloliquefaciens [28]. Transcriptomic analysis was also conducted to analyze critical genes involved in the infection 
process of B. cinerea [58], as well as the resistance-related genes of the B. cinerea B05.10 strain in response to fungicide cyprodinil and fenhexamid [57]. In this research, we showed the effective inhibitory effect of $\varepsilon$-PL on S. sclerotina, as well as on B. cinerea, and compared the effects of $\varepsilon$-PL between two typical necrotrophic pathogenic fungi by revealing regulatory trends on the critical genes and pathways of the pathogen.

Metabolic processes are required for the growth, as well as reproduction, of all kinds of microorganisms [34]. Carbon sources, such as glucose, maltose and fructose, as well as nitrogen sources, could be determining factors affecting fungal growth and sclerotia formation [59]. The results of the RNA-seq showed that many DEGs involved in carbohydrate or amino acid metabolism, such as alpha-amylase, glutaminase and serine carboxypeptidase, were reduced by $\varepsilon$-PL in $S$. sclerotiorum or B. cinerea, which indicated that the agent could suppress the basal metabolisms of the fungi, resulting in a decrease in fungal growth and sclerotia formation. Phosphatidylserine decarboxylase (PSDs) can be classified into two types, and the deletion mutants of PSDs cause severe growth defects and the malformation of Aspergillus nidulans [39]. Therefore, the inhibitory effect of $\varepsilon$-PL on the expression of SsPSD (SS1G_04563) may also result in the decreased fungal growth of S. sclerotiorum. The meiotic activator, RIM4, was reported to play an important role in the early events of meiosis in Saccharomyces cerevisiae [40]. Here, $\varepsilon$-PL treatment markedly suppressed the expression of the meiotic activator SsRIM4 (SS1G_03997), which suggested a possible inhibition of fungal cell meiosis by the agent treatment.

Plant cell walls are the first barrier against pathogenic fungal invasion [60]. To overcome the cell wall, $S$. sclerotiorum secretes numerous cell-wall-degrading enzymes (CWDEs) such as polygalacturonases, exo- $\beta-1,3$-glucanases, xylanases, and cellulases, which are detected during the early stages of infection [61]. In addition, cutinases are characterized as extracellular serine esterases that break the ester bond of cutin from the cuticle of plant [44]. In this study, the decrease in the gene expression of $\beta-1,3$-glucanases, pectate lyase, as well as cutinases ( $S s c u t$ and $B c c u t$ ), by $\mathcal{E}$ - PL can result in a reduction in the pathogenicity of $S$. sclerotiorum and B. cinerea. The largest group of proteases (including carboxypeptidases or subtilisin-like proteins) induced during fungal infection are serine proteases, which are characterized as virulence determinants in a large number of plant pathogenic fungi [45]. Here, our results showed that $\varepsilon$-PL suppressed the expression of the serine carboxypeptidase (SS1G_12413), which may reduce the virulence and pathogenicity of the fungus.

Botcinic acid and derivatives produced by $B$. cinerea were characterized as important phytotoxins, inducing host chlorosis or necrosis [62], and the genes involved in botcinic acid biosynthesis were designated as $B C B O A 1$ to $B C B O A 17$ [46]. Our results showed that the gene expressions of several $B C B O A$ s, such as $B C B O A 1$ and $B C B O A 2$, were markedly decreased by $\varepsilon$-PL, which could effectively suppress the infection of $B$. cinerea. The genes, $S s B O A 1$ to $S s B O A 13$, were identified as having a high similarity with $B c B O A 1$ to $B c B O A 13$, but were probably not related to the biosynthesis of secondary metabolites [46].

Osmotic stress and oxidative stress were often associated with reactive oxygen species (ROS) production [63]. Massive ROS, which led to oxidative bursts, was proven to exhibit a significant antimicrobial activity, such as the inhibition of the spore germination of a number of fungal pathogens [64]. Catalases are ubiquitous enzymes which prevent cell oxidative damage caused by stress responses by degrading hydrogen peroxide with a high efficiency [48]. The heat shock proteins (Hsps) are well-characterized, stress-inducible molecular chaperones, ubiquitously present in all forms of life [65]. Collectively, the upregulation of genes, such as Catalase $A$ and Hsps by $\varepsilon$-PL treatment, suggest the significant stress responses induced by the agent.

When exposed to xenobiotics or toxins, fungal cytochrome P450s (CYP450s) play critical roles in phase I of xenobiotic detoxification by converting these compounds to comparatively hydrophilic derivatives [49]. Recent RNA-sequencing and molecular genetics approaches validated that three CYP450s (CYP561, CYP65, and CYP68) were involved in the resistance to multiple fungicide classes mediated by xenobiotic detoxification [49]. Next, 
the fungus utilizes conjugating enzymes for phase II detoxification and efflux transporters, such as $A B C$ transporters, or major facilitator superfamily (MFS) transporters for phase III detoxification [66]. It was reported that the $A B C$ transporters, $A \operatorname{tr} A$ and $A \operatorname{trG}$, were involved in the azole drug resistance in Aspergillus oryzae [53]. In this study, $\varepsilon$-PL induced significant up-regulated expressions in many lines of genes in the cytochrome P450 family, glutathione S-transferase, ABC transporter family and MFS transporters in S. sclerotiorum and $B$. cinerea. The results indicated that $\varepsilon$-PL could induce the major detoxification pathways of the fungi.

In this research, we investigated the inhibitory effects and global gene regulation by a microbial source agent, $\varepsilon-\mathrm{PL}$, on two representative necrotrophic fungi and collectively summarized our data (Figure 7). The $\varepsilon$-PL was expected to be a green pesticide, which effectively suppressed the mycelial growth and regulated the expression of the critical genes and pathways involved in the pathogenicity, metabolism, stress responses and detoxification of S. sclerotiorum and B. cinerea. However, the precise inhibitory modes, such as the molecular target of $\varepsilon$-PL on the fungi-host interaction, remain to be further elucidated in future studies. This work will significantly improve the understanding of $\varepsilon$-PL action and the sustainable management of plant diseases caused by S. sclerotiorum and B. cinerea.

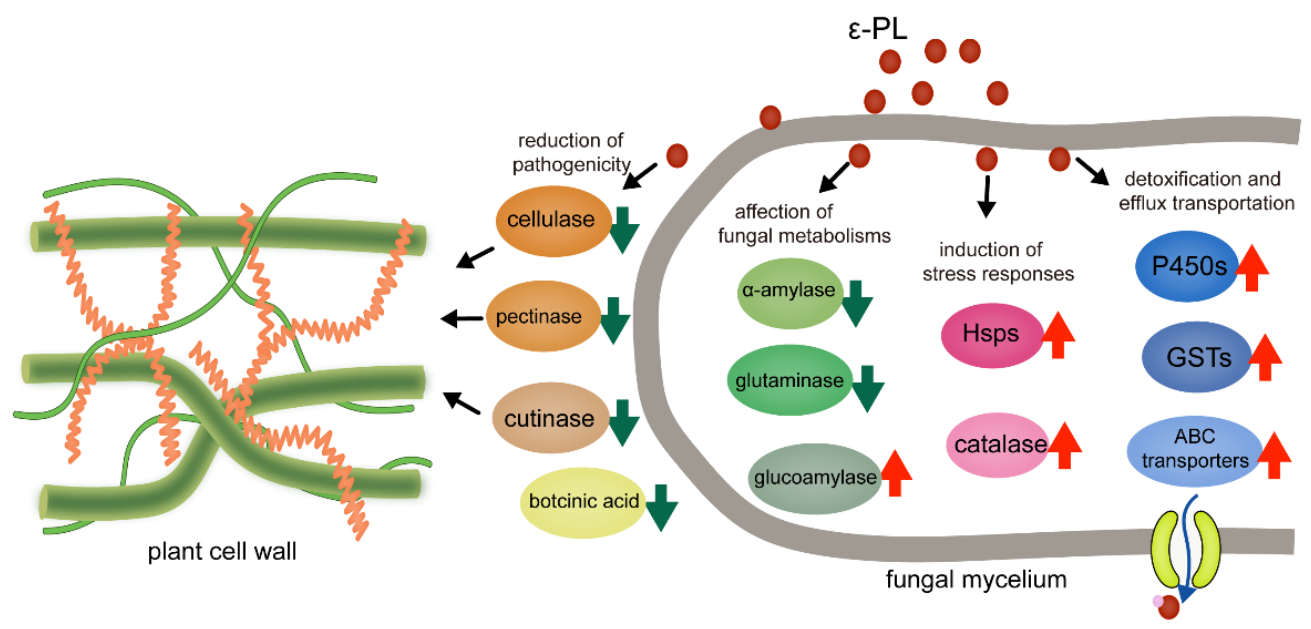

Figure 7. Model for regulation of critical genes involved in fungal metabolisms, pathogenicity, stress responses and detoxification by $\varepsilon$-PL treatment of two necrotrophic fungi.

Supplementary Materials: The following are available online at https:/ /www.mdpi.com/article/10 $.3390 /$ jof7100821/s1, Figure S1: Histogram GO enrichment of DEGs (a) S. sclerotiorum (b) B. cinerea, Table S1: Inhibitory effect of $\varepsilon$-PL against S. sclerotiorum and B. cinerea in vitro, Table S2: Read numbers aligned onto the $S$. sclerotiorum $(\mathrm{Ss})$ and B. cinerea $(\mathrm{Bc})$ genome by Illumina sequencing, Table S3: Total DEGs of $\varepsilon$-PL-responsive S. sclerotiorum transcriptome, Table S4: Total DEGs of $\varepsilon$-PL-responsive B. cinerea transcriptome, Table S5: Nucleic acid sequences of oligonucleotide primers used in RT-qPCR analysis.

Author Contributions: Conceptualization, M.A. and Y.W.; methodology, T.Z., H.L., Y.H. and Z.W.; software, T.Z., H.L., Y.S. and Y.H.; validation, T.Z., M.A. and H.L.; formal analysis, T.Z., Y.L. and Y.Y.; investigation, Y.H., Z.W. and Z.X.; resources, Y.W. and M.A.; data curation, T.Z., Y.H. and M.A.; writing-original draft preparation, T.Z., H.L. and M.A.; writing-review and editing, M.A., Y.L., Z.X. and Y.W.; visualization, H.L.; supervision, Y.W.; project administration, M.A. and Y.W.; funding acquisition, M.A. and Y.W. All authors have read and agreed to the published version of the manuscript.

Funding: This research was funded by Natural Science Foundation of China (32072391), National Key R\&D Program of China (2017YFE04900) and Fundamental Research Program for Liaoning Higher Education Institutions (LSNJC201914). 
Institutional Review Board Statement: Not applicable.

Informed Consent Statement: Not applicable.

Data Availability Statement: All raw data of RNA-seq are available at Sequence Read Archive (PRJNA749671, PRJNA749479).

Conflicts of Interest: The authors declare no conflict of interest.

\section{References}

1. van Bruggen, A.H.; Finckh, M.R. Plant diseases and management approaches in organic farming systems. Annu. Rev. Phytopathol. 2016, 54, 25-54. [CrossRef]

2. Liang, X.; Rollins, J.A. Mechanisms of broad host range necrotrophic pathogenesis in Sclerotinia sclerotiorum. Phytopathology 2018, 108, 1128-1140. [CrossRef]

3. Xu, L.; Li, G.; Jiang, D.; Chen, W. Sclerotinia sclerotiorum: An evaluation of virulence theories. Annu. Rev. Phytopathol. 2018, 56, 311-338. [CrossRef]

4. Boland, G.J.; Hall, R. Index of plant hosts of Sclerotinia sclerotiorum. Can. J. Plant. Pathol. 1994, 16, 93-108. [CrossRef]

5. Bolton, M.D.; Thomma, B.P.; Nelson, B.D. Sclerotinia sclerotiorum (Lib.) de Bary: Biology and molecular traits of a cosmopolitan pathogen. Mol. Plant. Pathol. 2006, 7, 1-16. [CrossRef]

6. Tian, J.; Chen, C.; Sun, H.; Wang, Z.; Steinkellner, S.; Feng, J.; Liang, Y. Proteomic analysis reveals the importance of exudates on sclerotial development in Sclerotinia sclerotiorum. J. Agric. Food Chem. 2021, 69, 1430-1440. [CrossRef]

7. Billon-Grand, G.; Rascle, C.; Droux, M.; Rollins, J.A.; Poussereau, N. pH modulation differs during sunflower cotyledon colonization by the two closely related necrotrophic fungi Botrytis cinerea and Sclerotinia sclerotiorum. Mol. Plant. Pathol. 2012, 13, 568-578. [CrossRef] [PubMed]

8. Amselem, J.; Cuomo, C.A.; van Kan, J.A.; Viaud, M.; Benito, E.P.; Couloux, A.; Coutinho, P.M.; de Vries, R.P.; Dyer, P.S.; Fillinger, S.; et al. Genomic analysis of the necrotrophic fungal pathogens Sclerotinia sclerotiorum and Botrytis cinerea. PLoS Genet. 2011, 7, e1002230. [CrossRef] [PubMed]

9. De Simone, N.; Pace, B. Botrytis cinerea and table grapes: A review of the main physical, chemical, and Bio-based control treatments in post-harvest. Foods 2020, 9, 1138. [CrossRef] [PubMed]

10. Jiao, W.; Li, X.; Wang, X.; Cao, J.; Jiang, W. Chlorogenic acid induces resistance against Penicillium expansum in peach fruit by activating the salicylic acid signaling pathway. Food Chem. 2018, 260, 274-282. [CrossRef]

11. Forté, C.A.; Colacino, J.; Polemi, K.; Guytingco, A.; Peraino, N.J.; Jindaphong, S.; Kaviya, T.; Westrick, J.; Neitzel, R.; Nambunmee, K. Pesticide exposure and adverse health effects associated with farmwork in Northern Thailand. J. Occup. Health 2021, 63, e12222. [CrossRef] [PubMed]

12. Peng, Y.; Li, S.J.; Yan, J.; Tang, Y.; Cheng, J.P.; Gao, A.J.; Yao, X.; Ruan, J.J.; Xu, B.L. Research progress on phytopathogenic fungi and their role as biocontrol agents. Front. Microbiol. 2021, 12, 670135. [CrossRef] [PubMed]

13. Li, S.; Yang, B.; Tan, G.Y.; Ouyang, L.M.; Qiu, S.; Wang, W.; Xiang, W.; Zhang, L. Polyketide pesticides from actinomycetes. Curr. Opin. Biotech. 2021, 69, 299-307. [CrossRef]

14. Quinn, G.A.; Banat, A.M.; Abdelhameed, A.M.; Banat, I.M. Streptomyces from traditional medicine: Sources of new innovations in antibiotic discovery. J. Med. Microbiol. 2020, 69, 1040-1048. [CrossRef] [PubMed]

15. Shima, S.; Sakai, H. Polylysine produced by Streptomyces. Agric. Biol. Chem. 1977, 41, 1807-1809. [CrossRef]

16. Li, S.; Tang, L.; Chen, X.; Liao, L.; Li, F.; Mao, Z. Isolation and characterization of a novel epsilon-poly-L-lysine producing strain: Streptomyces griseofuscus. J. Ind. Microbiol. Biot. 2011, 38, 557-563. [CrossRef]

17. Li, Y.; Han, Q.; Feng, J.; Tian, W.; Mo, H. Antibacterial characteristics and mechanisms of $\varepsilon$-poly-lysine against Escherichia coli and Staphylococcus aureus. Food Control. 2014, 43, 22-27. [CrossRef]

18. Hamano, Y. Occurrence, biosynthesis, biodegradation, and industrial and medical applications of a naturally occurring epsilonpoly-L-lysine. Biosci. Biotech. Bioch. 2011, 75, 1226-1233. [CrossRef]

19. Delihas, N.; Riley, L.W.; Loo, W.; Berkowitz, J.; Poltoratskaia, N. High-sensitivity of mycobacterium species to the bactericidal activity by polylysine. FEMS Microbiol. Lett. 1995, 132, 233-237. [CrossRef]

20. Shima, S.; Matsuoka, H.; Iwamoto, T.; Sakai, H. Antimicrobial action of epsilon-poly-L-lysine. J. Antibiot. 1984, 37, 1449-1455. [CrossRef]

21. Liu, H.; Chen, J.; Xia, Z.; An, M.; Wu, Y. Effects of $\varepsilon$-poly-L-lysine on vegetative growth, pathogenicity and gene expression of Alternaria alternata infecting Nicotiana tabacum. Pestic. Biochem. Physiol. 2020, 163, 147-153. [CrossRef]

22. Liu, K.; Zhou, X.; Fu, M. Inhibiting effects of epsilon-poly-lysine ( $\varepsilon$-PL) on Pencillium digitatum and its involved mechanism. Postharvest Biol. Technol. 2017, 123, 94-101. [CrossRef]

23. Jiao, W.; Liu, X.; Chen, Q.; Du, Y.; Li, Y.; Yue, F.; Dong, X.; Fu, M. Epsilon-poly-L-lysine ( $\varepsilon-P L)$ exhibits antifungal activity in vivo and in vitro against Botrytis cinerea and mechanism involved. Postharvest Biol. Technol. 2020, 168, 111270. [CrossRef]

24. Chen, J.; Liu, H.; Xia, Z.; Zhao, X.; Wu, Y.; An, M. Purification and structural analysis of the effective anti-TMV compound “ $\varepsilon$-Poly-L-lysine produced by Streptomyces ahygroscopicus. Molecules 2019, 24, 1156. [CrossRef] [PubMed] 
25. Liu, H.; Zhao, X.; Yu, M.; Meng, L.; Zhou, T.; Shan, Y.; Liu, X.; Xia, Z.; An, M.; Wu, Y. Transcriptomic and functional analyses indicate novel anti-viral mode of actions on tobacco mosaic virus of a microbial natural product $\varepsilon$-Poly-L-lysine. J. Agric. Food Chem. 2021, 69, 2076-2086. [CrossRef] [PubMed]

26. Sun, G.; Yang, Q.; Zhang, A.; Guo, J.; Liu, X.; Wang, Y.; Ma, Q. Synergistic effect of the combined bio-fungicides $\varepsilon$-poly-L-lysine and chitooligosaccharide in controlling gray mould (Botrytis cinerea) in tomatoes. Int. J. Food Microbiol. 2018, 276, 46-53. [CrossRef]

27. Shen, T.; Wang, Q.; Li, C.; Zhou, B.; Li, Y.; Liu, Y. Transcriptome sequencing analysis reveals silver nanoparticles antifungal molecular mechanism of the soil fungi Fusarium solani species complex. J. Hazard. Mater. 2020, 388, 122063. [CrossRef]

28. Yang, X.; Zhang, L.; Xiang, Y.; Du, L.; Huang, X.; Liu, Y. Comparative transcriptome analysis of Sclerotinia sclerotiorum revealed its response mechanisms to the biological control agent, Bacillus amyloliquefaciens. Sci. Rep. 2020, 10, 12576. [CrossRef]

29. Liang, Y.; Xiong, W.; Steinkellner, S.; Feng, J. Deficiency of the melanin biosynthesis genes SCD1 and THR1 affects sclerotial development and vegetative growth, but not pathogenicity, in Sclerotinia sclerotiorum. Mol. Plant. Pathol. 2018, 19, 1444-1453. [CrossRef]

30. An, M.; Tong, Z.; Ding, C.; Wang, Z.; Sun, H.; Xia, Z.; Qi, M.; Wu, Y.; Liang, Y. Molecular characterization of the thaumatin-like protein PR-NP24 in tomato fruits. J. Agric. Food Chem. 2019, 67, 13001-13009. [CrossRef]

31. Sun, H.; Tian, J.; Steinkellner, S.; Liang, Y. Identification and characterization of Colletotrichum destructivum causing anthracnose on sunflower. Arch. Microbiol. 2020, 202, 1459-1467. [CrossRef]

32. Li, J.T.; Mu, W.H.; Veluchamy, S.; Liu, Y.Z.; Zhang, Y.H.; Pan, H.Y.; Rollins, J.A. The GATA-type IVb zinc-finger transcription factor SsNsd1 regulates asexual-sexual development and appressoria formation in Sclerotinia sclerotiorum. Mol. Plant. Pathol. 2018, 19, 1679-1689. [CrossRef]

33. Sun, G.Z.; Wang, H.; Shi, B.B.; Shangguan, N.N.; Wang, Y.; Ma, Q. Control efficiency and expressions of resistance genes in tomato plants treated with $\varepsilon$-poly-L-lysine against Botrytis cinerea. Pestic. Biochem. Physiol. 2017, 143, 191-198. [CrossRef]

34. Chubukov, V.; Gerosa, L.; Kochanowski, K.; Sauer, U. Coordination of microbial metabolism. Nat. Rev. Microbiol. 2014, 12, 327-340. [CrossRef]

35. Westrick, N.M.; Ranjan, A.; Jain, S.; Grau, C.R.; Smith, D.L.; Kabbage, M. Gene regulation of Sclerotinia sclerotiorum during infection of Glycine max: On the road to pathogenesis. BMC Genom. 2019, 20, 157. [CrossRef]

36. Xie, F.; Murray, J.D.; Kim, J.; Heckmann, A.B.; Edwards, A.; Oldroyd, G.E.; Downie, J.A. Legume pectate lyase required for root infection by rhizobia. Proc. Natl. Acad. Sci. USA 2012, 109, 633-638. [CrossRef] [PubMed]

37. Li, F.; Ma, F.; Zhao, H.; Zhang, S.; Wang, L.; Zhang, X.; Yu, H. A lytic polysaccharide monooxygenase from a white-rot fungus drives the degradation of lignin by a versatile peroxidase. Appl. Environ. Microb. 2019, 85, e02803-18. [CrossRef] [PubMed]

38. Kumar, P.; Satyanarayana, T. Microbial glucoamylases: Characteristics and applications. Crit. Rev. Biotechnol. 2009, 29, 225-255. [CrossRef] [PubMed]

39. Takagi, K.; Kikkawa, A.; Iwama, R.; Fukuda, R.; Horiuchi, H. Type II phosphatidylserine decarboxylase is crucial for the growth and morphogenesis of the filamentous fungus Aspergillus nidulans. J. Biosci. Bioeng. 2021, 131, 139-146. [CrossRef]

40. Deng, C.; Saunders, W.S. RIM4 encodes a meiotic activator required for early events of meiosis in Saccharomyces cerevisiae. Mol. Genet. Genom. 2001, 266, 497-504. [CrossRef]

41. Bhatt, K.; Lal, S.; Srinivasan, R.; Joshi, B. Molecular analysis of Bacillus velezensis KB 2216, purification and biochemical characterization of alpha-amylase. Int. J. Biol. Macromol. 2020, 164, 3332-3339. [CrossRef]

42. Amobonye, A.; Singh, S.; Pillai, S. Recent advances in microbial glutaminase production and applications-a concise review. Crit. Rev. Biotechnol. 2019, 39, 944-963. [CrossRef] [PubMed]

43. Bühlmann, M.; Walrad, P.; Rico, E.; Ivens, A.; Capewell, P.; Naguleswaran, A.; Roditi, I.; Matthews, K.R. NMD3 regulates both mRNA and rRNA nuclear export in African trypanosomes via an XPOI-linked pathway. Nucleic Acids Res. 2015, 43, 4491-4504. [CrossRef] [PubMed]

44. Dallal Bashi, Z.; Rimmer, S.R.; Khachatourians, G.G.; Hegedus, D.D. Factors governing the regulation of Sclerotinia sclerotiorum cutinase A and polygalacturonase 1 during different stages of infection. Can. J. Microbiol. 2012, 58, 605-616. [CrossRef] [PubMed]

45. Muszewska, A.; Stepniewska-Dziubinska, M.M.; Steczkiewicz, K.; Pawlowska, J.; Dziedzic, A.; Ginalski, K. Fungal lifestyle reflected in serine protease repertoire. Sci. Rep. 2017, 7, 9147. [CrossRef] [PubMed]

46. Dalmais, B.; Schumacher, J.; Moraga, J.; Pêcheur, P.L.E.; Tudzynski, B.; Collado, I.G.; Viaud, M. The Botrytis cinerea phytotoxin botcinic acid requires two polyketide synthases for production and has a redundant role in virulence with botrydial. Mol. Plant. Pathol. 2011, 12, 564-579. [CrossRef]

47. Sales, K.; Brandt, W.; Rumbak, E.; Lindsey, G. The LEA-like protein HSP 12 in Saccharomyces cerevisiae has a plasma membrane location and protects membranes against desiccation and ethanol-induced stress. Biochim. Biophys. Acta 2000, 1463, 267-278. [CrossRef]

48. Alfonso-Prieto, M.; Biarnés, X.; Vidossich, P.; Rovira, C. The molecular mechanism of the catalase reaction. J. Am. Chem. Soc. 2009, 131, 11751-11761. [CrossRef] [PubMed]

49. Sang, H.; Hulvey, J.P.; Green, R.; Xu, H.; Im, J.; Chang, T.; Jung, G. A xenobiotic detoxification pathway through transcriptional regulation in filamentous fungi. mBio 2018, 9, e00457-18. [CrossRef]

50. Vela-Corcía, D.; Aditya Srivastava, D.; Dafa-Berger, A.; Rotem, N.; Barda, O.; Levy, M. MFS transporter from Botrytis cinerea provides tolerance to glucosinolate-breakdown products and is required for pathogenicity. Nat. Commun. 2019, 10, 2886. [CrossRef] 
51. Moreno, A.; Banerjee, A.; Prasad, R.; Falson, P. PDR-like ABC systems in pathogenic fungi. Res. Microbiol. 2019, 170, 417-425. [CrossRef]

52. Barski, O.A.; Tipparaju, S.M.; Bhatnagar, A. The aldo-keto reductase superfamily and its role in drug metabolism and detoxification. Drug Metab. Rev. 2008, 40, 553-624. [CrossRef]

53. Miura, D.; Sugiyama, K.; Ito, A.; Ohba-Tanaka, A.; Tanaka, M.; Shintani, T.; Gomi, K. The PDR-type ABC transporters AtrA and AtrG are involved in azole drug resistance in Aspergillus oryzae. Biosci. Biotech. Bioch. 2018, 82, 1840-1848. [CrossRef]

54. Ajay, K.P.; Awanish, K. Improved microbial biosynthesis strategies and multifarious applications of the natural biopolymer epsilon-poly-L-lysine. Process. Biochem. 2014, 49, 496-505.

55. Shu, C.; Cui, K.B.; Li, Q.Q.; Cao, J.K.; Jiang, W.B. Epsilon-poly-l-lysine ( $\varepsilon$-PL) exhibits multifaceted antifungal mechanisms of action that control postharvest Alternaria rot. Int. J. Food Microbiol. 2021, 348, 109224. [CrossRef]

56. Purev, E.; Kondo, T.; Takemoto, D.; Niones, J.T.; Ojika, M. Identification of $\varepsilon$-Poly-L-lysine as an antimicrobial product from an epichloë endophyte and isolation of fungal $\varepsilon$-PL synthetase gene. Molecules 2020, 25, 1032. [CrossRef]

57. Wang, X.; Gong, C.; Zhao, Y.; Shen, L. Transcriptome and resistance-related genes analysis of Botrytis cinerea B05.10 strain to different selective pressures of cyprodinil and fenhexamid. Front. Microbiol. 2018, 9, 2591. [CrossRef] [PubMed]

58. Reboledo, G.; Agorio, A.; Vignale, L.; Batista-García, R.A.; Ponce De León, I. Botrytis cinerea transcriptome during the infection process of the Bryophyte Physcomitrium patens and angiosperms. J. Fungi. 2020, 7, 11. [CrossRef] [PubMed]

59. Sun, X.; Liu, D.; Wang, Y.; Ma, A. Biogenesis of macrofungal sclerotia: Influencing factors and molecular mechanisms. Appl. Microbiol. Biot. 2020, 104, 4227-4234. [CrossRef]

60. Kubicek, C.P.; Starr, T.L.; Glass, N.L. Plant cell wall-degrading enzymes and their secretion in plant-pathogenic fungi. Annu. Rev. Phytopathol. 2014, 52, 427-451. [CrossRef] [PubMed]

61. Oliveira, M.B.; Barbosa, S.C.; Petrofeza, S. Comparative in vitro and in planta analyses of extracellular enzymes secreted by the pathogenic fungus Sclerotinia sclerotiorum. Genet. Mol. Res. 2013, 12, 1796-1807. [CrossRef] [PubMed]

62. Cutler, H.G.; Parker, S.R.; Ross, S.A.; Crumley, F.G.; Schreiner, P.R. Homobotcinolide: A biologically active natural homolog of botcinolide from Botrytis cinerea. Biosci. Biotech. Bioch. 1996, 60, 656-658. [CrossRef] [PubMed]

63. Liu, L.; Wang, Q.; Sun, Y.; Zhang, Y.; Zhang, X.; Liu, J.; Yu, G.; Pan, H. Sssfh1, a gene encoding a putative component of the RSC chromatin remodeling complex, is involved in hyphal growth, reactive oxygen species accumulation, and pathogenicity in Sclerotinia sclerotiorum. Front. Microbiol. 2018, 9, 1828. [CrossRef] [PubMed]

64. Mousavi, S.A.A.; Robson, G.D. Oxidative and amphotericin B-mediated cell death in the opportunistic pathogen Aspergillus fumigatus is associated with an apoptotic-like phenotype. Microbiology 2004, 150, 1937-1945. [CrossRef] [PubMed]

65. Richter, K.; Haslbeck, M.; Buchner, J. The heat shock response: Life on the verge of death. Mol. Cell 2010, 40, 253-266. [CrossRef] [PubMed]

66. Vanden Bossche, H.; Koymans, L. Cytochromes P450 in fungi. Mycoses 1998, 41, 32-38. [CrossRef] [PubMed] 